\title{
Genomic analysis of the origins of extant casein variation in goats
}

\author{
D. Guan, ${ }^{1}$ E. Mármol-Sánchez, ${ }^{1}$ T. F. Cardoso,${ }^{1,2}$ X. Such,${ }^{3}$ V. Landi, ${ }^{4}$ N. R. Tawari, ${ }^{5}$ and M. Amills ${ }^{1,3 *}$ \\ ${ }^{1}$ Department of Animal Genetics, Centre for Research in Agricultural Genomics (CRAG), Consejo Superior de Investigaciones \\ Científicas-Institut de Recerca i Tecnologia Agroalimentàries-Universitat Autònoma de Barcelona-Universitat de Barcelona (CSIC-IRTA-UAB-UB), \\ Campus Universitat Autònoma de Barcelona, Bellaterra 08193, Spain \\ ${ }^{2}$ CAPES Foundation, Ministry of Education of Brazil, Brasilia D.F., 70.040-020 Brazil \\ ${ }^{3}$ Departament de Ciència Animal i dels Aliments, Facultat de Veterinària, Universitat Autònoma de Barcelona, Bellaterra 08193, Spain \\ ${ }^{4}$ Departamento de Genética, Universidad de Córdoba, Córdoba 14071, Spain \\ ${ }^{5}$ Computational and Systems Biology, Genome Institute of Singapore, 60 Biopolis Street, Genome, \#02-01, Singapore 138672
}

\section{ABSTRACT}

The variation in the casein genes has a major impact on the milk composition of goats. Even though many casein polymorphisms have been identified so far, we do not know yet whether they are evolutionarily ancient (i.e., they existed before domestication) or young (i.e., they emerged after domestication). Herewith, we identified casein polymorphisms in a data set of 106 caprine whole-genome sequences corresponding to bezoars (Capra aegagrus, the ancestor of domestic goats) and 4 domestic goat (Capra hircus) populations from Europe, Africa, the Far East, and the Near East. Domestic and wild goat populations shared a substantial number of casein SNP, from $36.1 \%$ (CSN2) to $55.1 \%$ (CSN1S2). The comparison of casein variation among bezoars and the 4 domestic goat populations demonstrated that more than $50 \%$ of the casein SNP are shared by 2 or more populations, and 18 to $44 \%$ are shared by all populations. Moreover, the majority of casein alleles reported in domestic goats also segregate in the bezoar, including several alleles displaying significant associations with milk composition (e.g., the A/B alleles of the CSN1S1 and CSN3 genes, the A allele of the CSN2 gene). We conclude that much of the current diversity of the caprine casein genes comes from ancient standing variation segregating in the ancestor of modern domestic goats.

Key words: domestication, standing variation, nextgeneration sequencing, single nucleotide polymorphism

\section{INTRODUCTION}

Caseins represent $80 \%$ of the protein content of milk and they have a major impact on dairy traits, as well as on cheese yield and texture (Remeuf et al., 1991). Goat

Received June 26, 2018.

Accepted February 5, 2019.

*Corresponding author: marcel.amills@uab.cat caseins $\alpha_{S 1}, \alpha_{S 2}, \beta$, and $\kappa$ are encoded by the CSN1S1, CSN1S2, CSN2, and CSN3 genes, respectively, which map to a $250-\mathrm{kb}$ region on chromosome 6 in the order CSN1S1-CSN2-CSN1S2-CSN3 (Rijnkels, 2002). Polymorphisms in these 4 genes have been implicated in the variation of milk yield and composition (protein and fat contents) as well as in the determination of milk rheological properties and the yield and organoleptic attributes of cheese (reviewed in Martin et al., 1999; Moioli et al., 2007; Amills et al., 2012).

The domestication of the bezoar (Capra aegagrus) in the Fertile Crescent 10,000 yr before present resulted in the domestic goat (Capra hircus), an important economic resource in developing countries (Zeder and Hesse 2000; Naderi et al., 2008). Even though many reports describing the variability of goat casein genes have been published (Martin et al., 2002; Moioli et al., 2007; Amills, 2014), we do not know yet whether casein polymorphisms are evolutionarily ancient (i.e., they existed before domestication) or young (i.e., they emerged after domestication). We addressed this question by identifying casein polymorphisms from 106 caprine whole-genome sequences and comparing the allelic variation of the 4 casein genes in (1) 2 populations: bezoars and domestic goats, (2) 5 populations: bezoars and 4 groups of domestic goats from Europe, Africa, the Far East, and Near East. We aimed to determine whether extant genetic variation in the goat casein genes was present before domestication (as standing variation segregating in the bezoar) or if it emerged in the context of the evolutionary processes that took place during and after domestication.

\section{MATERIALS AND METHODS}

\section{Retrieval of Goat Whole-Genome Sequences}

Whole-genome sequences from 110 wild and domestic goats (Becker et al., 2015; Benjelloun et al., 2015; Reber et al., 2015; Menzi et al., 2016; Wang et al., 2016; Li et 
al., 2017; Alberto et al., 2018) were retrieved from the National Center for Biotechnology Information (NCBI) Sequence Read Archive (SRA, https://www.ncbi.nlm .nih.gov/sra; Supplemental Table S1, https://doi.org/ 10.3168/jds.2018-15281). Specifically, this data set included genome sequences from bezoars $(\mathrm{n}=22)$ as well as 4 domestic goat populations from Europe (Alpine, $\mathrm{n}=2$; Chamois Colored, $\mathrm{n}=2$; Grisons Striped, $\mathrm{n}=$ 1; Saanen, $\mathrm{n}=6$; Coppernecked, $\mathrm{n}=1$; Tessin Grey, $\mathrm{n}=1$ ), Africa (local Moroccan population, $\mathrm{n}=20$ ), the Far East (Inner Mongolia Cashmere goat, $\mathrm{n}=9$, Liaoning Cashmere goat, $\mathrm{n}=10$; Tibetan goat, $\mathrm{n}=$ 16 ), and Near East (local Iranian breed, $\mathrm{n}=20$ ). We retrieved all goat genome sequences that were available at the time of initiating our experiment. All raw data in SRA format were converted into the fastq format by using the fastq-dump 2.8.2 tool available in the SRAtoolkits package (https://www.ncbi.nlm.nih.gov/sra/ docs/toolkitsoft/).

\section{Discovery and Annotation of Genomic Variants}

To obtain high-quality SNP and insertion/deletions (INDEL), fastq files were filtered with the Trimommatic software (version 0.36, Bolger et al., 2014). Only paired-end reads were used in the alignment step. Sequences were aligned to the goat reference genome (ARS1, Bickhart et al., 2017) with the BWA MEM algorithm with default settings (Li, 2013). Files in sequence alignment map (SAM) format were sorted and converted into binary format to remove PCR duplicates and to realign INDEL regions with the Picard tool (https://broadinstitute.github.io/picard/). The HaplotypeCaller function of the Genome Analysis Toolkit (GATK, version 3.8) was used to generate vcf (variant call format) files by considering default parameters (McKenna et al., 2010). Finally, a hard filtering step was performed by following the GATK best practices recommendations. The SNP data set was then imputed and phased by using the Beagle 4.1 software (Browning and Browning, 2016) to improve genotype calls based on genotype likelihoods.

\section{Investigation of Population Structure}

We used the autosomal SNP identified with GATK (McKenna et al., 2010) to investigate the population structure of bezoars and domestic goats. A thinned set of autosomal SNP was selected with the command "-hwe 0.001 --maf 0.05 --geno 0.3 --indep-pairwise 505 0.2" of the PLINK v1.9 software (Purcell et al., 2007). Beforehand, individuals with pi-hat values, estimated based on an identity-by-descent (IBD) matrix, above
0.4 were removed from the data set to avoid biases produced by relatedness. By doing so, 4 individuals (2 EU and 2 FE goats) were excluded and the final data set was based on 106 caprine genomes. A neighborjoining tree was constructed with the MEGA7 software (Kumar et al., 2016) based on an identity-by-state (IBS) distance matrix (Purcell et al., 2007). Principal components analyses (PCA) based on 11,226,125 SNP with a whole-genome distribution and 1,221 SNP mapping to the casein genes were performed with PLINK v1.9 software (Purcell et al., 2007) by using the flag "--pca" with default parameters. In addition, the Admixture software (version 1.3.0, Alexander et al., 2009) was used to estimate population structure with a block relaxation algorithm. The number of clusters (K-value) went from 2 to 5 , and the K-value with the lowest crossvalidation error was identified by using the method of Alexander and Lange (2011). Moreover, we repeated the Admixture analysis considering just the data set of 1,221 SNP mapping to the casein genes.

\section{Annotating the Variation of Caprine Casein Genes}

The genomic coordinates of the goat casein genes (CSN1S1, CSN2, CSN1S2, and CSN3) in the ARS1 reference genome (Bickhart et al., 2017) were used to retrieve polymorphisms mapping to these 4 loci with VCFtools 1.8 (Danecek et al., 2011; https://samtools .github.io/bcftools/bcftools.html). Casein polymorphisms were classified and their effects were predicted with the SnpEff 4.3 software (Cingolani et al., 2012). Moreover, the SIFT Annotator (Vaser et al., 2016) was used to predict deleteriousness of missense SNP. When the SIFT predicted score is $<0.05$, an AA substitution is classified as deleterious (Vaser et al., 2016); otherwise, it is tolerated or neutral. By following the strategy outlined in Supplemental Figure S1 (https://doi.org/ 10.3168/jds.2018-15281), we were able to convert sequence data into casein alleles or groups of alleles. This classification, which was based on information provided by Marletta et al. (2007), took into account several missense mutations that are outlined in Supplemental Figure S1. We were unable to discriminate between the $\mathrm{B} 4$ and E alleles of the CSN1S1 gene because we could not trace the presence of the LINE insertion characteristic of the E allele (repetitive elements are usually filtered out before the alignment step). The SnpEff 4.3 software did not detect any mutation introducing a premature stop codon, so we did not identify null alleles in the casein genes. It is difficult to know whether this was due to a biological reality (absence of null alleles in the analyzed populations) or to an annotation problem associated with SnpEff 4.3. In contrast, the O1 and 
O2 alleles of the CSN1S1 gene are large copy number variants whose genomic coordinates have not been reported at a fine resolution. They might be detectable using software such as Cn.MOPS or CNVnator, but the main limitation of our experiment was that we had a very heterogeneous data set composed of whole-genome sequences generated with different types of libraries, platforms, and, more importantly, coverages, so detecting copy number variants based on read depth would be inaccurate. We did not use INDEL information to classify alleles because we believe that INDEL calling from sequence data can be quite unreliable. Indeed, O'Rawe et al. (2013) compared the concordance rates among INDEL detected by the GATK Unified Genotyper (v1.5), SOAPindel (v1.0), and SAMtools (v0.1.18) and concluded that there was just $26.8 \%$ agreement across all 3 software programs. Hasan et al. (2015) compared the performance of 7 INDEL calling tools and reported that the number of common INDELs called by all 7 tools was very low. For this reason, we decided to report the B2, F, and D alleles as a group.

The nucleotide diversity ( $\pi$ value, average number of pairwise differences between all individuals in the population) of the casein loci (based on 1,221 SNP mapping to casein genes) was calculated with the VCFtools software (Danecek et al. 2011) by using the "--site-pi" command. The same conditions were used to estimate nucleotide diversity at the whole-genome level. All results in this study were visualized under the R software environment (https://www.r-project.org/).

\section{RESULTS}

\section{Genome-Wide Analysis of Population Structure}

By using a data set of 106 whole-genome sequences (Supplemental Table S1, https://doi.org/10.3168/jds .2018-15281) from domestic goats and bezoars, a total of 31 billion paired-end reads were mapped to the goat reference genome ARS1 (Bickhart et al., 2017). The average sequencing depth was $9.92 \times$ and the average mapping rate $>99 \%$ (Supplemental Table S1). Analysis of the sequence data with the GATK package (McKenna et al., 2010) made it possible to identify 51 million SNP. The majority of these SNP were biallelic, and only 509,001 sites displayed 3 or more alleles. Moreover, $35.17 \%$ of SNPs had minor allele frequencies (MAF) $>0.05$ (17.94 million), whereas rare (MAF between 0.01 and 0.05$)$ and very rare (MAF <0.01) SNP displayed frequencies of 29.72 and $36.74 \%$, respectively. The average ratio of transitions to transversions was 2.11 for the whole data set, a result consistent with previous reports (Guan et al., 2016; Li et al., 2017).
After filtering, 11,226,125 autosomal SNP were used to assess the population structure of the 106 bezoars and domestic goats (4 highly related individuals with pi-hat values $>0.4$ were removed). The PCA and the neighbor-joining tree (Figures 1a and 1b) showed that individuals clustered according to their geographic origin. In the PCA, bezoars and domestic goats from the Near East occupied an intermediate position between Far East goats and those from Europe and Africa. Moreover, Far East domestic goats formed a tight cluster, whereas bezoars had a more scattered distribution (Figure $1 \mathrm{~b}$ ). At $\mathrm{K}=2$, the Admixture analysis showed the existence of 2 different backgrounds in domestic goats: Africa/Europe and Far East, whereas Near East goats displayed an intermediate or admixed background (Figure 2). At the K-value with the lowest cross-validation error $(\mathrm{K}=3)$, bezoars formed a distinctive group clearly differentiated from domestic goats (Figure 2). At $\mathrm{K}=4$, we observed the existence of 2 genetically differentiated subgroups in Far East goats, whereas at $\mathrm{K}=5$, European and African goats displayed different genetic backgrounds (Figure 2). When we repeated the PCA and Admixture analysis by using a panel of 1,221 SNP mapping to the casein genes, we observed a substantial weakening of population structure (Supplemental Figure S2, https://doi.org/10.3168/jds.2018-15281). This result might be because this second analysis was based on a very reduced set of SNP (1,221 SNP versus $11,226,125$ SNPs used in the first analysis).

\section{Characterization of Variation in Goat Casein Genes}

We identified hundreds of SNP in the CSN1S1 (455 SNP, 6 missense), CSN2 (194 SNP, 5 missense), CSN1S2 (292 SNP, 11 missense), and CSN3 (280 SNPs, 9 missense) genes (Table 1, Supplemental Tables S2, S3, and S4, https://doi.org/10.3168/jds.2018-15281). In the 4 casein genes, most SNP were intronic, and the second most abundant category was represented by SNP located in upstream and downstream genic regions (Supplemental Table S4). Annotation of SNP with the SnpEff software (Cingolani et al., 2012) showed that the majority of casein polymorphisms were expected to have low or moderate effects. Indeed, only 1 SNP (g.85982647G >A), affecting a splice site in the CSN1S1 gene ( $\mathrm{G}$ allele), was predicted to have a high impact (Supplemental Tables S2 to S4). The SIFT annotator (Vaser et al., 2016) captured additional missense SNP predicted to be functionally relevant (Supplemental Tables S2 to S4). Additionally, most casein SNP identified in our investigation had MAF >0.05 (47.1\%), a result consistent with that obtained in the analysis of genome-wide diversity. With regard to INDEL, we 

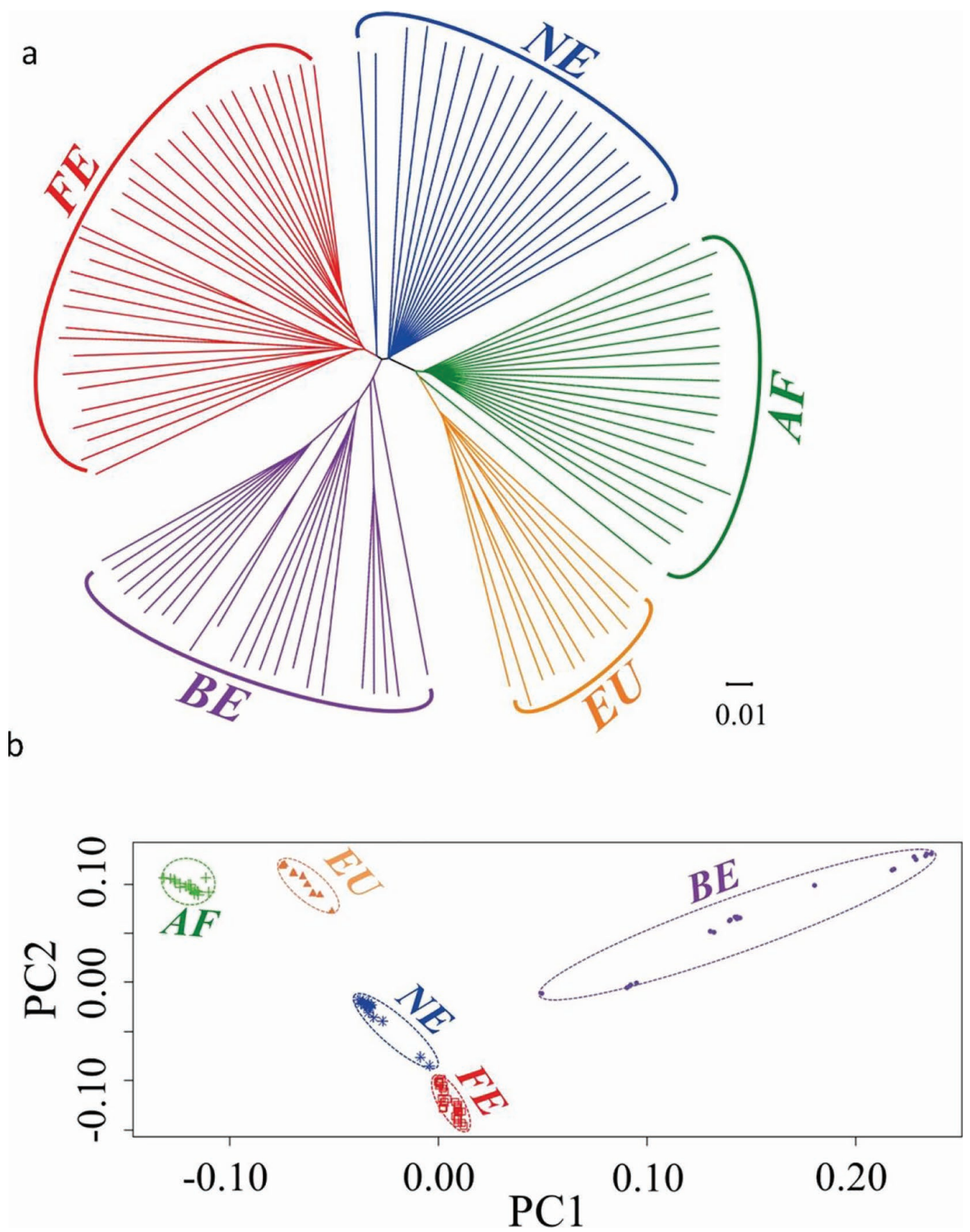

Figure 1. (a) Neighbor-joining tree, and (b) principal components analysis (PCA) of 106 bezoars (BE) and domestic goats from Europe (EU), Africa (AF), Near East (NE), and Far East (FE) based on a data set of 11,226,125 autosomal SNP. The neighbor-joining tree was built according to an identity-by-state (IBS) distance matrix constructed with the PLINK software (Purcell et al., 2007) with default parameters. The PCA considered principal components (PC) 1 and 2, which explained 14.20\% (6.20/eigenvalues) and 13.54\% (5.91/eigenvalues) of the variance, respectively.

found 81 in CSN1S1, 25 in CSN2, 59 in CSN1S2, and 49 in CSN3 (Supplemental Table S2). However, we did not use INDELs in subsequent analyses because INDEL calling remains an error-prone process and the rate of false positives might be high because of alignment artifacts and to the fact that most of the INDEL calling tools lack accurate methods for checking sequencing errors before calling INDEL (Hasan et al. 2015). Indeed, 

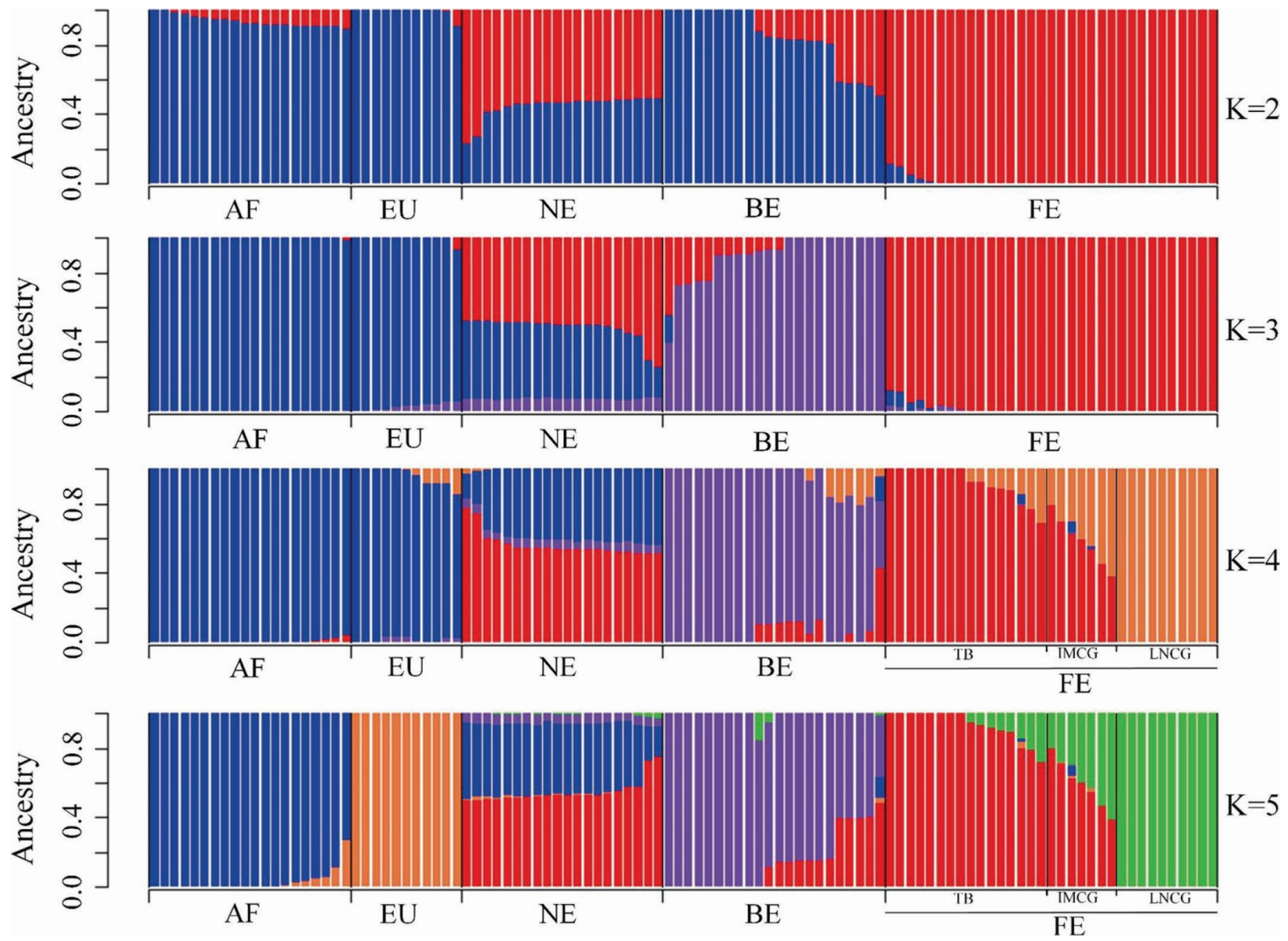

Figure 2. Analysis using Admixture software (version 1.3.0, Alexander et al., 2009) of 106 bezoars (BE) and domestic goats from Europe (EU), Africa (AF), Near East (NE), and Far East (FE) based on a data set of 11,226,125 autosomal SNP. Each colored bar represents one individual and the length represents the proportion of the goat genome inherited from each ancestral population. In the Far East group, the following subpopulations are indicated: Tibetan (TB), Inner Mongolia Cashmere goats (IMCG), and Liaoning Cashmere goats (LNCG). The $\mathrm{K}$-value defines the number of clusters.

concordance rates of INDEL calls between algorithms and sequencing platforms are reportedly low (Fang et al. 2014).

We analyzed casein SNP variation of bezoars and domestic goats (Figure 3). Domestic and wild populations shared a substantial number of casein SNP, from $36.1 \%$ (CSN2) to $55.1 \%$ (CSN1S2). The comparison of casein variation among the 5 populations (bezoars and domestic goats from Europe, Africa, Near East, and Far East) also showed that more than $50 \%$ of casein SNP are shared by 2 or more populations and $18 \%$ (CSN3) to $44 \%$ (CSN1S1) of SNP are shared by all populations (Figure 3). Nucleotide diversity in the casein loci was similar in bezoar and domestic goat populations (Figure 4a), with the exception of Far East goats, which showed a reduced level of variation $(t$-test, $P<0.05)$. Moreover, the nucleotide diversity of the casein loci was higher ( $t$-test, $P<0.001$ ) than that observed along the autosomal genome (Figure $4 \mathrm{~b}$ ).

We used the pipeline reported in Supplemental Figure S1 (https://doi.org/10.3168/jds.2018-15281) to detect casein alleles or groups of alleles based on sequence data (Table 1). In the CSN1S1 gene, the A/I/N/O group of alleles was quite frequent in all populations, with an average frequency $>0.5$. Moreover, we were able to detect combinations of SNP that did not correspond to any of the CSN1S1 alleles cataloged by Marletta et al. (2007); for example, $\quad \mathrm{H}_{8} \mathrm{P}_{16} \mathrm{Q}_{77} \mathrm{R}_{100} \mathrm{~A}_{195}, \quad \mathrm{H}_{8} \mathrm{~L}_{16} \mathrm{Q}_{77} \mathrm{R}_{100} \mathrm{~A}_{195}$, $\mathrm{H}_{8} \mathrm{P}_{16} \mathrm{Q}_{77} \mathrm{R}_{100} \mathrm{~T}_{195}$, and $\mathrm{H}_{8} \mathrm{~L}_{16} \mathrm{E}_{77} \mathrm{~K}_{100} \mathrm{~A}_{195}$. These novel haplotypes were especially frequent in Far East goats. 
Table 1. Frequencies of alleles or groups of alleles identified in bezoars and domestic goats from Africa, Europe, Far East, and Near East in the current study

\begin{tabular}{llccccc}
\hline Casein gene & Allele & $\begin{array}{c}\text { Bezoar } \\
(\mathrm{n}=22)\end{array}$ & $\begin{array}{c}\text { Africa } \\
(\mathrm{n}=20)\end{array}$ & $\begin{array}{c}\text { Europe } \\
(\mathrm{n}=11)\end{array}$ & $\begin{array}{c}\text { Far East } \\
(\mathrm{n}=33)\end{array}$ & $\begin{array}{c}\text { Near East } \\
(\mathrm{n}=20)\end{array}$ \\
\hline CSN1S1 & A-I-N-O1-O2 & 0.55 & 0.30 & 0.27 & 0.57 & 0.67 \\
& B1 & 0.02 & 0 & 0 & 0.03 & 0 \\
$(\mathrm{n}=106)$
\end{tabular}

In the CSN1S2, CSN2, and CSN3 genes, the most abundant alleles were A (average frequency $=0.54$ ), $\mathrm{C}$ (average frequency $=0.67$ ), and $\mathrm{A} / \mathrm{B}$ (average frequency $=0.68)$, respectively. We also identified certain alleles in CSN1S1 (B1, C and G), CSN1S2 (E), and CSN3 (I, K, and $\mathrm{M}$ ) that are rare (average frequency $<0.05$ ) or very rare (average frequency $<0.01$ ). Five of these rare alleles were present in Far East goats at low frequencies, and 2 ( $\mathrm{K}$ and I alleles of the CSN3 gene) segregated exclusively in this population. We were unable to identify the D allele of the CSN1S2 gene, and the null alleles plus the A1 allele of the CSN2 gene remained undetected in our data set.

In certain cases, frequencies of casein alleles were quite divergent among populations. For instance, the $\mathrm{H}$ allele of the CSN3 gene was relatively common in Far East goats but rare in goats from Africa, Europe, or the Near East (Table 1), and the D allele of the CSN3 gene was quite frequent in goats from the Near and Far East but completely absent in the remaining caprine populations (Table 1). In the CSN1S1 gene, the B3 allele segregated at moderate frequencies in African goats but did not segregate in the European population. Importantly, we found that the majority of casein alleles were present in the population of bezoars, indicating that their existence probably predates domestication. This finding was further supported by the segregation of the majority of casein alleles in two or more of the analyzed populations (Table 1), despite the fact that the populations are separated by considerable geographic distances.

\section{DISCUSSION}

A relevant evolutionary question that we aimed to answer in the current study was whether extant casein genetic variation segregating in domestic goats comes from standing variation (already present in bezoars before their domestication) or whether it emerged after goat domestication and dispersal (novel variation). Before analyzing casein variation, we investigated the genetic relationships and population structure of the 5 caprine populations under analysis (bezoars and goats from Europe, Africa, Near East, and Far East). Our results showed that individuals clustered according to their geographic origin (Figure 1). Goats were domesticated in a geographic area from the Central Zagros Mountains (Iran) to Eastern Anatolia (Zeder and Hesse, 2000; Naderi et al., 2008; reviewed in Pereira and Amorim, 2010) and subsequently spread into Europe, Africa, and Asia (Pereira and Amorim, 2010). The existence of genetic differentiation between the 5 populations analyzed in our study (Figure 1) is compatible with the hypothesis that different gene pools migrated through the Mediterranean and Danubian corridors in Europe, the Central Steppe and the Indus Valley in 
Asia, and North Africa (Pereira and Amorim, 2010). Indeed, the analysis of goat ancient genomes has shown that goats were domesticated at multiple locations (and time periods) in the Fertile Crescent (Daly et al., 2018). Genetic drift combined with the existence of differences in breed management, reproductive isolation, and selection goals probably contributed to the establishment of genetic differences between Asian, European, and African goats.

The analysis of population structure using Admixture analysis showed the existence of Western (Africa and Europe) and Eastern (Far East) genetic backgrounds, whereas the genetic background of Near Eastern domestic goats shared both components $(\mathrm{K}=$ 3, Figure 2). The third distinctive genetic background was represented by bezoars from the Near East $(K=$ 3, Figure 2). Analysis of mitochondrial variation of Iranian wild boars revealed segregation not only of Middle East haplotypes but also of haplotypes that are typically found in wild boars from the West (Europe and Africa) and Far East (Khalilzadeh et al., 2016). These results highlight that Iran has been an important contact zone between the East and the West, and also a key hotspot of genetic diversity (Khalilzadeh et al.,
2016). Moreover, we also detected the existence of 2 different backgrounds in Far East goats, reflecting the existence of 2 different populations ( $\mathrm{K}=5$, Figure 2); that is, Tibetan goats and 2 Cashmere breeds (Wang et al., 2016; Li et al., 2017). Inner Mongolia Cashmere goats displayed a genetic background intermediate between that of Tibetan and Liaoning Cashmere goats (Figure 2). This result points to the Mongolian Plateau being a critical hub for the dispersal of goats across East Asia (Pereira and Amorim, 2010), as reported for cattle (Ajmone-Marsan et al., 2010) and sheep (Zhao et al., 2017).

We annotated casein polymorphisms according to the genomic coordinates provided in the ARS1 assembly of the goat genome (Bickhart et al., 2017). Obviously, this annotation may differ from that used in previous publications. For instance, the missense CSN3 Asn74Ser and Val86Ile polymorphisms identified by us (Supplemental Table S2, https://doi.org/10.3168/jds.2018-15281) correspond to the Asn53Ser and Val65Ile substitutions reported by Marletta et al. (2007). These differences might be due, for instance, to the fact that AA residue numbering in a protein sequence may begin with the first AA of either the leader peptide or the mature
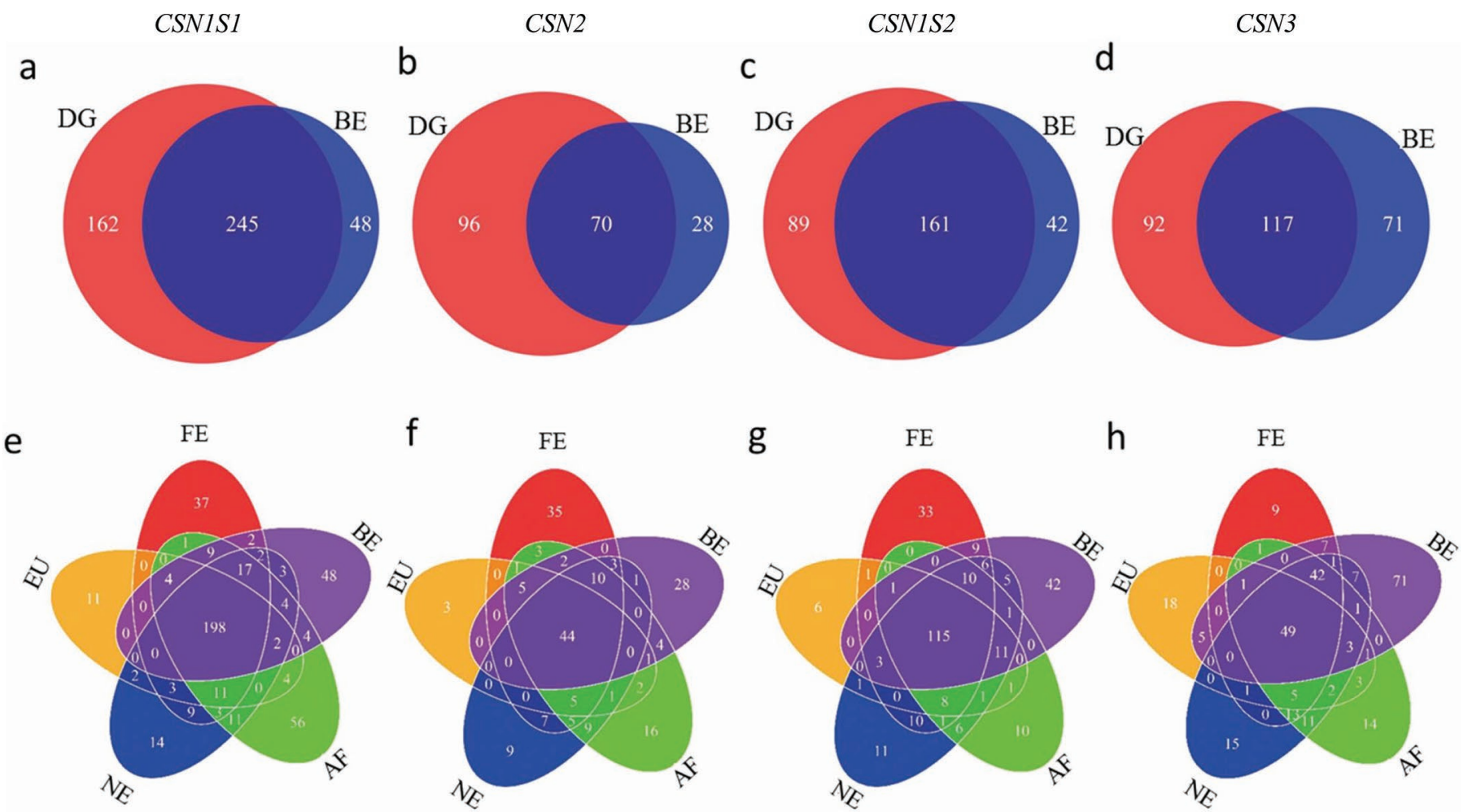

Figure 3. (a-d) Venn diagrams depicting the $\alpha_{\mathrm{S1}^{-}}$(CSN1S1), $\alpha_{\mathrm{S2}^{-}}$(CSN1S2), $\beta$ - (CSN2), and $\kappa-$ (CSN3) casein SNP shared between bezoars (BE) and domestic goats (DG); (e to h) Venn diagrams depicting CSN1S1, CSN1S2, CSN2, and CSN3 SNP shared between bezoars (BE) and domestic goats from Europe (EU), Africa (AF), Near East (NE), and Far East (FE). 
a

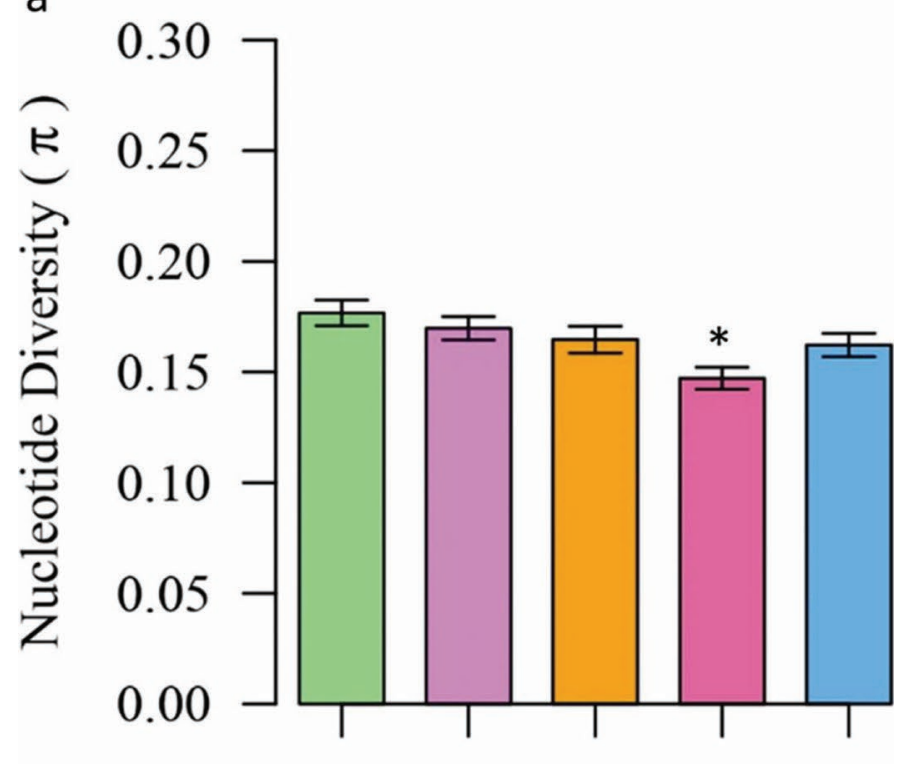

AF BE EU FE NE

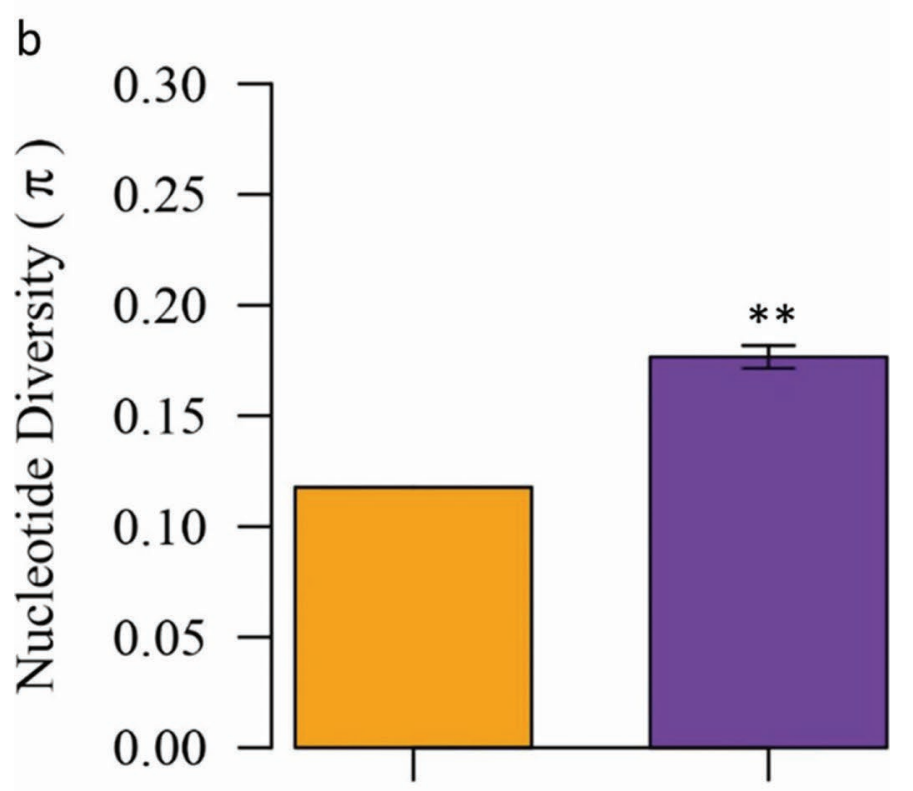

Genome Level

Casein Loci

Figure 4. Nucleotide diversity of (a) the casein loci in bezoars (BE) and domestic goats from Africa (AF), Europe (EU), Near East (NE), and Far East (FE), and (b) the casein loci compared with the autosomal genome. Each bar represents the mean nucleotide diversity and its standard error. The standard error $\left(2.08 \times 10^{-5}\right)$ of the estimate of the nucleotide diversity corresponding to the autosomal genome is very small, so it is not depicted in the graph. *The nucleotide diversity of the Far East population was significantly lower $(P<$ $0.05)$ than those of the other populations. ${ }^{* *}$ Nucleotide diversities of whole-genome and casein genes were significantly different $(P<0.01)$. protein sequence. Moreover, whole-genome sequencing with a modest coverage (average of $9.92 \times$ in the current work) can yield thousands of false polymorphisms that are produced by sequencing errors (Robasky et al., 2014). However, these drawbacks should not have a major effect on the main conclusions of our study because we did not intend to build a curated catalog of casein variation in goats, which will eventually be reported in the Ensembl database (https://www.ensembl.org). Rather, we aimed to investigate the geographic distribution of caprine casein variation to make inferences about the origins of such variation (i.e., to ascertain whether it arose from standing or novel variation).

The comparison of the nucleotide diversity of the casein loci in bezoars versus domestic goats showed that they have similar levels of variation (Figure 4a). However, goats from the Far East displayed lower levels of diversity, a feature that might be due to an ancient founder effect associated with goat dispersal after domestication. Moreover, the nucleotide diversity of the casein loci was higher than that observed in the autosomal genome (Figure 4b). Two preferential recombination sites have been reported in the casein cluster (Bevilacqua et al., 2002; Hayes et al., 2006), a circumstance that is known to promote the generation of diversity. Moreover, the casein genes are not essential to sustain life, so purifying selection is probably less intense than in other genomic regions that contain housekeeping genes.

In the 4 casein genes, a substantial number of SNP (36-55\%) were shared between the wild and domestic forms. Importantly, the number of analyzed bezoars was relatively low, so we cannot rule out the possibility that the percentage of shared variation between bezoars and domestic goats will increase if sample size is augmented. The variation shared between wild and domestic goats might have an ancestral origin, but such a pattern could also be produced by an introgression of the bezoar population with domestic goats. However, the analysis of Figure 1 does not provide evidence of introgressed bezoars in our data set. Moreover, the comparison of casein polymorphisms across the 5 populations showed that more than $50 \%$ of the polymorphisms were shared between 2 or more populations, and that between 18 and $44 \%$ were shared by all populations. Casein diversity shared by all 5 populations probably has an ancestral origin (i.e., its existence probably predates the post-domestication dispersal of goats). These results indicate that a considerable proportion of casein variation might have been present in the bezoar before the domestication process.

Our findings agree well with other studies demonstrating that genetic variants of agricultural importance 
such as those related to tomato fruit size, maize plant architecture (e.g., teosinte branched 1), seasonality controls, and seed size were already present as standing variation in the wild progenitors of domestic plant species (Larson et al., 2014). One exception to this general trend would be that of mutations that could be deleterious in the wild but not in a domestic context; however, in principle, mutations with functional consequences on the casein genes are not expected to have any effect on the biological efficacy of the individuals harboring them. These results contrast strongly with those obtained in dogs, where several mutations with large phenotypic effects are present in dogs but not in wolves, implying that these mutations emerged during or after domestication and reached detectable allelic frequencies because they were selected for (Boyko et al., 2010; Larson et al., 2014). We also observed that a relevant fraction of casein diversity is not shared across populations (Figure 3). This variation might be represented by mutations that emerged after the domestication and dispersal of goats or may be caused by insufficient sampling or to sequencing errors (because of limited genomic coverage).

The allelic frequencies of the casein genes reported in Table 1 were consistent with those of previous studies, although it is important to emphasize that such frequencies can be very variable even when comparing breeds reared in the same geographic location; for example, the CSN1S1 A and E alleles are the most frequent alleles in Italian Saanen and Alpine breeds (Frattini et al., 2014), whereas the most abundant CSN1S1 allele in Sarda goats is B (Vacca et al., 2014). In the CSN1S1 gene, we observed that the A-I-N-O1-O2, B2-D-F, and $\mathrm{B} 4-\mathrm{E}$ groups of alleles were well represented in the European and African populations (Table 1). Genotyping of CSN1S1 in French (Grosclaude et al., 1994; Pepin, 1994; Carillier-Jacquin et al., 2016) and Italian (Sacchi et al., 2005; Caroli et al., 2006; Gigli et al., 2008; Mastrangelo et al., 2013; Frattini et al., 2014) goats showed that the $\mathrm{A}$ and $\mathrm{F}$ alleles are quite abundant, whereas in Spanish (Jordana et al., 1996; Caravaca et al., 2008) and African (Caroli et al., 2007) goats, the $\mathrm{B} / \mathrm{E}$ and $\mathrm{A} / \mathrm{B}$ pairs of alleles are the most frequent, respectively. In contrast, the $\mathrm{C}, \mathrm{G}, \mathrm{N}$, and $\mathrm{O} 1$ alleles tend to have low frequencies in Italian (Sacchi et al., 2005; Caroli et al., 2006; Gigli et al., 2008; Mastrangelo et al., 2013; Frattini et al., 2014) and African breeds (Caroli et al., 2007). According to our results (Table 1), the A-I-N-O1-O2 group of alleles is prevalent in Near East and Far East domestic goats as well as in bezoars. A previous study on Indian and Turkish goats (Chessa et al., 2007) reflected the same trend, with high frequencies of the A allele in the majority of the analyzed populations. With regard to the CSN1S2 and CSN2 genes, we found that the $\mathrm{A}$ and $\mathrm{C}$ alleles, respectively, were predominant, a finding consistent with what has been published in European, African, Turkish, and Indian goats (Sacchi et al., 2005; Caroli et al., 2006, 2007; Chessa et al., 2007; Gigli et al., 2008; Vacca et al., 2014; Tortorici et al., 2014; Kusza et al., 2016; Grobler et al., 2017). In the CSN3 gene, the $\mathrm{A}$ and $\mathrm{B}$ alleles were predominant in most populations (Table 1), as previously published in a broad array of caprine breeds (Yahyaoui et al., 2003; Prinzenberg et al., 2005; Caroli et al., 2007; Chessa et al., 2007; Kiplagat et al., 2010; Di Gerlando et al., 2015). Interestingly, the D allele was frequent in Far East and Near East goats, and the G/L group of alleles was found in Near East goats and bezoars (Table 1). The genetic analysis of the CSN3 locus in Turkish and Indian goats shows that the D allele is relatively frequent, and that the $\mathrm{G}$ allele also segregates in these 2 populations but at lower frequencies (Prinzenberg et al., 2005; Chessa et al., 2007). The CSN3 D and G alleles, in contrast, are rare in African (Caroli et al., 2007) and most European breeds (Yahyaoui et al. 2003; Prinzenberg et al., 2005), with the exception of several Italian populations (Sacchi et al., 2005; Di Gerlando et al., 2015).

In summary, our main finding was that a significant number of casein alleles (or groups of alleles) are present in the bezoar, suggesting that they existed before domestication. Of note, several of the casein alleles detected in the bezoar have been associated with dairy traits in domestic goats. For instance, the A and B alleles of the CSN1S1 gene determine a high content of $\alpha_{S_{1}}$-casein in milk and they increase milk protein, casein, and fat contents and improve cheese yield (reviewed in Martin et al., 1999; Moioli et al., 2007; Amills et al., 2012; Amills, 2014). The A allele of the CSN2 gene and the $\mathrm{B}$ allele of the CSN3 gene are also associated with a higher protein content (Caravaca et al., 2009; Vacca et al., 2014). We found that several CSN3 polymorphisms that are very rare in European breeds were more frequent in goat populations from other continents, emphasizing the need to investigate their effects on dairy traits.

\section{CONCLUSIONS}

The main conclusion of this work is that a relevant fraction of the casein variation segregating in domestic goats probably emerged before the domestication process.

\section{ACKNOWLEDGMENTS}

This research was funded by grant AGL2016-76108-R awarded by the Spanish Ministry of Economy and 
Competitivity (Madrid, Spain). We also acknowledge the support of the Spanish Ministry of Economy and Competitivity for the Center of Excellence Severo Ochoa 2016-2019 (SEV-2015-0533) grant awarded to the Centre for Research in Agricultural Genomics (CRAG, Bellaterra, Spain). Dailu Guan was funded by a PhD fellowship from the China Scholarship Council (CSC). Emilio Mármol-Sánchez was funded by a FPU $\mathrm{PhD}$ grant from the Spanish Ministry of Education (FPU15/01733). Tainã Figueiredo Cardoso was funded by a fellowship from the CAPES Foundation-Coordination of Improvement of Higher Education, Ministry of Education of the Federal Government of Brazil. The authors thank the CERCA Programme of the Generalitat de Catalunya (Barcelona, Spain) for their support and those who provided publicly available data.

\section{REFERENCES}

Ajmone-Marsan, P., J. F. Garcia, and J. A. Lenstra. 2010. On the origin of cattle: How aurochs became cattle and colonized the world. Evol. Anthropol. 19:148-157. https://doi.org/10.1002/evan.20267.

Alberto, F. J., F. Boyer, P. Orozco-ter Wengel, I. Streeter, B. Servin, P. de Villemereuil, B. Benjelloun, P. Librado, F. Biscarini, L. Colli, M. Barbato, W. Zamani, A. Alberti, S. Engelen, A. Stella, S. Joost, P. Ajmone-Marsan, R. Negrini, L. Orlando, H. R. Rezaei, S. Naderi, L. Clarke, P. Flicek, P. Wincker, E. Coissac, J. Kijas, G. Tosser-Klopp, A. Chikhi, M. W. Bruford, P. Taberlet, and F. Pompanon. 2018. Convergent genomic signatures of domestication in sheep and goats. Nat. Commun. 9:813. https://doi.org/10.1038/ s41467-018-03206-y.

Alexander, D. H., and K. Lange. 2011. Enhancements to the ADMIXTURE algorithm for individual ancestry estimation. BMC Bioinformatics 12:246. https://doi.org/10.1186/1471-2105-12-246.

Alexander, D. H., J. Novembre, and K. Lange. 2009. Fast model-based estimation of ancestry in unrelated individuals. Genome Res. 19:1655-1664. https://doi.org/10.1101/gr.094052.109.

Amills, M. 2014. The application of genomic technologies to investigate the inheritance of economically important traits in goats. Adv. Biol. 13. https://doi.org/10.1155/2014/904281.

Amills, M., J. Jordana, A. Zidi, and J. M. Serradilla. 2012. Genetic factors that regulate milk protein and lipid composition in goats. In Milk Production-Advanced Genetic Traits, Cellular Mechanism, Animal Management and Health. N. Chaiyabutr, ed. InTech, Rijeka, Croatia. https://doi.org/10.5772/51716.

Becker, D., M. Otto, P. Ammann, I. Keller, C. Drögemüller, and T. Leeb. 2015. The brown coat colour of Coppernecked goats is associated with a non-synonymous variant at the TYRP1 locus on chromosome 8. Anim. Genet. 46:50-54. https://doi.org/10.1111/ age. 12240

Benjelloun, B., F. J. Alberto, I. Streeter, F. Boyer, E. Coissac, S. Stucki, M. BenBati, M. Ibnelbachyr, M. Chentouf, A. Bechchari, K. Leempoel, A. Alberti, S. Engelen, A. Chikhi, L. Clarke, P. Flicek, S. Joost, P. Taberlet, and F. Pompanon., and NextGen Consortium. 2015. Characterizing neutral genomic diversity and selection signatures in indigenous populations of Moroccan goats (Capra hircus) using WGS data. Front. Genet. 6:107. https://doi .org/10.3389/fgene.2015.00107.

Bevilacqua, C., P. Ferranti, G. Garro, C. Veltri, R. Lagonigro, C. Leroux, E. Pietrolà, F. Addeo, F. Pilla, L. Chianese, and P. Martin. 2002. Interallelic recombination is probably responsible for the occurrence of a new $\alpha_{\mathrm{S}^{1}}$-casein variant found in the goat species. Eur. J. Biochem. 269:1293-1303.

Bickhart, D. M., B. D. Rosen, S. Koren, B. L. Sayre, A. R. Hastie, S. Chan, J. Lee, E. T. Lam, I. Liachko, S. T. Sullivan, J. N. Burton,
H. J. Huson, J. C. Nystrom, C. M. Kelley, J. L. Hutchison, Y. Zhou, J. Sun, A. Crisa, F. A. Ponce de Leon, J. C. Schwartz, J. A. Hammond, G. C. Waldbieser, S. G. Schroeder, G. E. Liu, M. J. Dunham, J. Shendure, T. S. Sonstegard, A. M. Phillippy, C. P. Van Tassell, and T. P. L. Smith. 2017. Single-molecule sequencing and chromatin conformation capture enable de novo reference assembly of the domestic goat genome. Nat. Genet. 49:643-650. https://doi.org/10.1038/ng.3802.

Bolger, A. M., M. Lohse, and B. Usadel. 2014. Trimmomatic: A flexible trimmer for Illumina sequence data. Bioinformatics 30:21142120. https://doi.org/10.1093/bioinformatics/btu170.

Boyko, A. R., P. Quignon, L. Li, J. J. Schoenebeck, J. D. Degenhardt, K. E. Lohmueller, K. Y. Zhao, A. Brisbin, H. G. Parker, B. M. vonHoldt, M. Cargill, A. Auton, A. Reynolds, A. G. Elkahloun, M. Castelhano, D. S. Mosher, N. B. Sutter, G. S. Johnson, J. Novembre, M. J. Hubisz, A. Siepel, R. K. Wayne, C. D. Bustamante, and E. A. Ostrander. 2010. A simple genetic architecture underlies morphological variation in dogs. PLoS Biol. 8:e1000451. https:// doi.org/10.1371/journal.pbio.1000451.

Browning, B. L., and S. R. Browning. 2016. Genotype imputation with millions of reference samples. Am. J. Hum. Genet. 98:116-126. https://doi.org/10.1016/j.ajhg.2015.11.020.

Caravaca, F., M. Amills, J. Jordana, A. Angiolillo, P. Agüera, C. Aranda, A. Menéndez-Buxadera, A. Sánchez, J. Carrizosa, B. Urrutia, A. Sànchez, and J. M. Serradilla. 2008. Effect of $\alpha_{S 1}$-casein (CSN1S1) genotype on milk CSN1S1 content in Malagueña and Murciano-Granadina goats. J. Dairy Res. 75:481-484. https://doi .org/10.1017/S0022029908003609.

Caravaca, F., J. Carrizosa, B. Urrutia, F. Baena, J. Jordana, M. Amills, B. Badaoui, A. Sánchez, A. Angiolillo, and J. M. Serradilla. 2009. Short communication: Effect of $\alpha_{\mathrm{S} 1}$-casein (CSN1S1) and $\mathrm{k}$-casein (CSN3) genotypes on milk composition in MurcianoGranadina goats. J. Dairy Sci. 92:2960-2964. https://doi.org/10 $.3168 /$ jds.2008-1510.

Carillier-Jacquin, C., H. Larroque, and C. Robert-Granié. 2016. Including $\alpha_{s 1}$ casein gene information in genomic evaluations of French dairy goats. Genet. Sel. Evol. 48:54. https://doi.org/10 $.1186 / \mathrm{s} 12711-016-0233-\mathrm{x}$.

Caroli, A., F. Chiatti, S. Chessa, D. Rignanese, P. Bolla, and G. Pagnacco. 2006. Focusing on the goat casein complex. J. Dairy Sci. 89:3178-3187. https://doi.org/10.3168/jds.S0022-0302(06)72592 $-9$.

Caroli, A., F. Chiatti, S. Chessa, D. Rignanese, E. M. Ibeagha-Awemu, and G. Erhardt. 2007. Characterization of the casein gene complex in West African goats and description of a new $\alpha_{\mathrm{S}_{1} \text {-casein poly- }}$ morphism. J. Dairy Sci. 90:2989-2996. https://doi.org/10.3168/ jds.2006-674.

Chessa, S., F. Chiatti, D. Rignanese, E. M. Ibeagha-Awemu, C. Özbeyaz, Y. A. Hassan, M. M. Baig, G. Erhardt, and A. Caroli. 2007. The casein genes in goat breeds from different continents: Analysis by polymerase chain reaction-single strand conformation polymorphism (PCR-SSCP). Ital. J. Anim. Sci. 6:73-75. https://doi.org/ 10.4081/ijas.2007.1s.73.

Cingolani, P., A. Platts, L. L. Wang, M. Coon, T. Nguyen, L. Wang, S. J. Land, X. Lu, and D. M. Ruden. 2012. A program for annotating and predicting the effects of single nucleotide polymorphisms, SnpEff: SNPs in the genome of Drosophila melanogaster strain $w^{1118}$; iso-2; iso-3. Fly (Austin) 6:80-92. https://doi.org/10 .4161/fly.19695.

Daly, K. G., P. Maisano Delser, V. E. Mullin, A. Scheu, V. Mattiangeli, M. D. Teasdale, A. J. Hare, J. Burger, M. P. Verdugo, M. J. Collins, R. Kehati, C. M. Erek, G. Bar-Oz, F. Pompanon, T. Cumer, C. Çakırlar, A. F. Mohaseb, D. Decruyenaere, H. Davoudi, Ö. Çevik, G. Rollefson, J.-D. Vigne, R. Khazaeli, H. Fathi, S. B. Doost, R. Rahimi Sorkhani, A. A. Vahdati, E. W. Sauer, H. Azizi Kharanaghi, S. Maziar, B. Gasparian, R. Pinhasi, L. Martin, D. Orton, B. S. Arbuckle, N. Benecke, A. Manica, L. K. Horwitz, M. Mashkour, and D. G. Bradley. 2018. Ancient goat genomes reveal mosaic domestication in the Fertile Crescent. Science 361:85-88. https://doi.org/10.1126/science.aas9411. 
Danecek, P., A. Auton, G. Abecasis, C. A. Albers, E. Banks, M. A. DePristo, R. E. Handsaker, G. Lunter, G. T. Marth, S. T. Sherry, G. McVean, and R. Durbin., and 1000 Genomes Project Analysis Group. 2011. The variant call format and VCFtools. Bioinformatics 27:2156-2158. https://doi.org/10.1093/bioinformatics/btr330.

Di Gerlando, R., L. Tortorici, M. T. Sardina, G. Monteleone, S. Mastrangelo, and B. Portolano. 2015. Molecular characterisation of $\kappa$-casein gene in Girgentana dairy goat breed and identification of two new alleles. Ital. J. Anim. Sci. 14:3464. https://doi.org/10 .4081/ijas.2015.3464.

Fang, H., Y. Y. Wu, G. Narzisi, J. A. O'Rawe, L. T. J. Barron, J. Rosenbaum, M. Ronemus, I. Iossifov, M. C. Schatz, and G. J. Lyon. 2014. Reducing INDEL calling errors in whole genome and exome sequencing data. Genome Med. 6:89. https://doi.org/10 $.1186 / \mathrm{s} 13073-014-0089-\mathrm{z}$.

Frattini, S., L. Nicoloso, B. Coizet, S. Chessa, L. Rapetti, G. Pagnacco, and P. Crepaldi. 2014. Short communication: The unusual genetic trend of $\alpha_{\mathrm{S}_{1}}$-casein in Alpine and Saanen breeds. J. Dairy Sci. 97:7975-7979. https://doi.org/10.3168/jds.2014-7780.

Gigli, I., D. O. Maizon, V. Riggio, M. T. Sardina, and B. Portolano, 2008. Short communication: Casein haplotype variability in Sicilian dairy goat breeds. J. Dairy Sci. 91:3687-3692. https://doi.org/ 10.3168/jds.2008-1067.

Grobler, R., C. Visser, S. Chessa, and E. van Marle-Köster. 2017. Genetic polymorphism of CSN1S2 in South African dairy goat populations. S. Afr. J. Anim. Sci. 47:72-78. https://doi.org/10 .4314/sajas.v47i1.11.

Grosclaude, F., G. Ricordeau, P. Martin, F. Remeuf, L. Vassal, and J. Bouillon. 1994. Du gène au fromage: Le polymorphisme de la caséine $\alpha_{S 1}$ caprine, ses effets, son évolution. INRA Prod. Anim. $7: 3-19$.

Guan, D., N. Luo, X. Tan, Z. Zhao, Y. Huang, R. Na, J. Zhang, and Y. Zhao. 2016. Scanning of selection signature provides a glimpse into important economic traits in goats (Capra hircus). Sci. Rep. 6:36372. https://doi.org/10.1038/srep36372.

Hasan, M. S., X. Wu, and L. Zhang. 2015. Performance evaluation of indel calling tools using real short-read data. Hum. Genomics 9:20. https://doi.org/10.1186/s40246-015-0042-2.

Hayes, B., N. Hagesæther, T. Ådnøy, G. Pellerud, P. R. Berg, and S. Lien. 2006. Effects on production traits of haplotypes among casein genes in Norwegian goats and evidence for a site of preferential recombination. Genetics 174:455. https://doi.org/10.1534/ genetics.106.058966.

Jordana, J., M. Amills, E. Díaz, C. Angulo, J. M. Serradilla, and A. Sànchez. 1996. Gene frequencies of caprine $\alpha_{\mathrm{s} 1}$-casein polymorphism in Spanish goat breeds. Small Rumin. Res. 20:215-221. https://doi.org/10.1016/0921-4488(95)00813-6.

Khalilzadeh, P., H. R. Rezaei, D. Fadakar, M. Serati, M. Aliabadian, J. Haile, and H. Goshtasb. 2016. Contact zone of Asian and European wild boar at North West of Iran. PLoS One 11:e0159499. https://doi.org/10.1371/journal.pone.0159499.

Kiplagat, S. K., M. Agaba, I. S. Kosgey, A. M. Okeyo, D. Indetie, O. Hanotte, and M. K. Limo. 2010. Genetic polymorphism of kappacasein gene in indigenous Eastern Africa goat populations. Int. J. Genet. Mol. Biol. 2:1-5.

Kumar, S., G. Stecher, and K. Tamura. 2016. MEGA7: Molecular Evolutionary Genetics Analysis version 7.0 for bigger datasets. Mol. Biol. Evol. 33:1870-1874. https://doi.org/10.1093/molbev/ msw054.

Kusza, S., D. E. Ilie, M. Sauer, K. Nagy, I. Patras, and D. Gavojdian. 2016. Genetic polymorphism of CSN2 gene in Banat White and Carpatina goats. Acta Biochim. Pol. 63:577-580. https://doi.org/ 10.18388/abp.2016_1266.

Larson, G., D. R. Piperno, R. G. Allaby, M. D. Purugganan, L. Andersson, M. Arroyo-Kalin, L. Barton, C. C. Vigueira, T. Denham, K Dobney, A. N. Doust, P. Gepts, M. T. P. Gilbert, K. J. Gremillion, L. Lucas, L. Lukens, F. B. Marshall, K. M. Olsen, J. C. Pires, P. J. Richerson, R. R. de Casas, O. I. Sanjur, M. G. Thomas, and D. Q. Fuller. 2014. Current perspectives and the future of domestication studies. Proc. Natl. Acad. Sci. USA 111:6139-6146. https://doi .org/10.1073/pnas.1323964111.
Li, H. 2013. Aligning sequence reads, clone sequences and assembly contigs with BWA-MEM. arXiv:1303.3997v2 [q-bio.GN].

Li, X., R. Su, W. Wan, W. Zhang, H. Jiang, X. Qiao, Y. Fan, Y. Zhang, R. Wang, Z. Liu, Z. Wang, B. Liu, Y. Ma, H. Zhang, Q. Zhao, T. Zhong, R. Di, Y. Jiang, W. Chen, W. Wang, Y. Dong, and J. Li. 2017. Identification of selection signals by large-scale whole-genome resequencing of cashmere goats. Sci. Rep. 7:15142. https://doi.org/10.1038/s41598-017-15516-0.

Marletta, D., A. Criscione, S. Bordonaro, A. M. Guastella, and G D'Urso. 2007. Casein polymorphism in goat's milk. Lait 87:491504.

Martin, P., M. Ollivier-Bousquet, and F. Grosclaude. 1999. Genetic polymorphism of caseins: A tool to investigate casein micelle organization. Int. Dairy J. 9:163-171. https://doi.org/10.1016/S0958 $-6946(99) 00055-2$

Martin, P., M. Szymanowska, L. Zwierzchowski, and C. Leroux. 2002. The impact of genetic polymorphisms on the protein composition of ruminant milks. Reprod. Nutr. Dev. 42:433-459. https://doi .org/10.1051/rnd:2002036.

Mastrangelo, S., M. T. Sardina, M. Tolone, and B. Portolano. 2013. Genetic polymorphism at the CSN1S1 gene in Girgentana dairy goat breed. Anim. Prod. Sci. 53:403-406. https://doi.org/10.1071/ $\mathrm{AN} 12242$.

McKenna, A., M. Hanna, E. Banks, A. Sivachenko, K. Cibulskis, A. Kernytsky, K. Garimella, D. Altshuler, S. Gabriel, M. Daly, and M. A. DePristo. 2010. The Genome Analysis Toolkit: A MapReduce framework for analyzing next-generation DNA sequencing data. Genome Res. 20:1297-1303. https://doi.org/10.1101/gr .107524 .110 .

Menzi, F., I. Keller, I. Reber, J. Beck, B. Brenig, E. Schutz, T. Leeb, and C. Drogemuller. 2016. Genomic amplification of the caprine EDNRA locus might lead to a dose dependent loss of pigmentation. Sci. Rep. 6:28438. https://doi.org/10.1038/srep28438.

Moioli, B., M. D'Andrea, and F. Pilla. 2007. Candidate genes affecting sheep and goat milk quality. Small Rumin. Res. 68:179-192. https: //doi.org/10.1016/j.smallrumres.2006.09.008.

Naderi, S., H. R. Rezaei, F. Pompanon, M. G. Blum, R. Negrini, H. R. Naghash, O. Balkiz, M. Mashkour, O. E. Gaggiotti, P. AjmoneMarsan, A. Kence, J. D. Vigne, and P. Taberlet. 2008. The goat domestication process inferred from large-scale mitochondrial DNA analysis of wild and domestic individuals. Proc. Natl. Acad. Sci. USA 105:17659-17664. https://doi.org/10.1073/pnas.0804782105.

O'Rawe, J., T. Jiang, G. Sun, Y. Wu, W. Wang, J. Hu, P. Bodily, L. Tian, H. Hakonarson, W. E. Johnson, Z. Wei, K. Wang, and G. J. Lyon. 2013. Low concordance of multiple variant-calling pipelines: Practical implications for exome and genome sequencing. Genome Med. 5:28.

Pepin, L. 1994. Recherche de polymorphisme genetique chez les caprins. Applications à l'étude de la diversité des populations, au contrôle de filiation et à la résistance génétique à la cowdriose. Doctoral Thesis. Universite de Paris XI Orsay, France.

Pereira, F., and A. Amorim. 2010. Origin and spread of goat pastoralism. In Encyclopedia of Life Sciences (eLS). John Wiley \& Sons Ltd., Chichester, UK. https://doi.org/10.1002/9780470015902 .a0022864.

Prinzenberg, E. M., K. Gutscher, S. Chessa, A. Caroli, and G. Erhardt. 2005. Caprine k-casein (CSN3) polymorphism: New developments in molecular knowledge. J. Dairy Sci. 88:1490-1498. https://doi .org/10.3168/jds.S0022-0302(05)72817-4.

Purcell, S., B. Neale, K. Todd-Brown, L. Thomas, M. A. R. Ferreira, D. Bender, J. Maller, P. Sklar, P. I. W. de Bakker, M. J. Daly, and P. C. Sham. 2007. PLINK: A tool set for whole-genome association and population-based analyses. Am. J. Hum. Genet. 81:559-575. https://doi.org/10.1086/519795.

Reber, I., I. Keller, D. Becker, C. Flury, M. Welle, and C. Drogemuller 2015. Wattles in goats are associated with the FMN1/GREM1 region on chromosome 10. Anim. Genet. 46:316-320. https://doi .org/10.1111/age.12279.

Remeuf, F., V. Cossin, C. Dervin, J. Lenoir, and R. Tomassone. 1991. Relationships between physico-chemical characteristics of milks and their cheese-making properties. Lait 71:397-421. 
Rijnkels, M. 2002. Multispecies comparison of the casein gene loci and evolution of casein gene family. J. Mammary Gland Biol. Neoplasia 7:327-345. https://doi.org/10.1023/A:1022808918013.

Robasky, K., N. E. Lewis, and G. M. Church. 2014. The role of replicates for error mitigation in next-generation sequencing. Nat. Rev. Genet. 15:56-62. https://doi.org/10.1038/nrg3655.

Sacchi, P., S. Chessa, E. Budelli, P. Bolla, G. Ceriotti, D. Soglia, R. Rasero, E. Cauvin, and A. Caroli. 2005. Casein haplotype structure in five Italian goat breeds. J. Dairy Sci. 88:1561-1568. https: //doi.org/10.3168/jds.S0022-0302(05)72825-3.

Tortorici, L., R. Di Gerlando, S. Mastrangelo, M. T. Sardina, and B. Portolano. 2014. Genetic characterisation of CSN2 gene in Girgentana goat breed. Ital. J. Anim. Sci. 13:3414. https://doi.org/10 .4081/ijas.2014.3414.

Vacca, G. M., M. L. Dettori, G. Piras, F. Manca, P. Paschino, and M. Pazzola. 2014. Goat casein genotypes are associated with milk production traits in the Sarda breed. Anim. Genet. 45:723-731. https://doi.org/10.1111/age.12188.

Vaser, R., S. Adusumalli, S. N. Leng, M. Sikic, and P. C. Ng. 2016. SIFT missense predictions for genomes. Nat. Protoc. 11:1. https:/ /doi.org/10.1038/nprot.2015.123.
Wang, X., J. Liu, G. Zhou, J. Guo, H. Yan, Y. Niu, Y. Li, C. Yuan, R. Geng, X. Lan, X. An, X. Tian, H. Zhou, J. Song, Y. Jiang, and Y. Chen. 2016. Whole-genome sequencing of eight goat populations for the detection of selection signatures underlying production and adaptive traits. Sci. Rep. 6:38932. https://doi.org/10.1038/ srep38932.

Yahyaoui, M. H., A. Angiolillo, F. Pilla, A. Sànchez, and J. M. Folch. 2003. Characterization and genotyping of the caprine $\kappa$-casein variants. J. Dairy Sci. 86:2715-2720. https://doi.org/10.3168/jds .S0022-0302(03)73867-3.

Zeder, M. A., and B. Hesse. 2000. The initial domestication of goats (Capra hircus) in the Zagros Mountains 10,000 years ago. Science 287:2254-2257. https://doi.org/10.1126/science.287.5461.2254.

Zhao, Y. X., J. Yang, F. Lv, X. Hu, X. Xie, M. Zhang, W. Li, M. Liu, Y. Wang, J. Li, Y. Liu, Y. Ren, F. Wang, E. Hehua, J. Kantanen, J. Arjen Lenstra, J. Han, and M. Li. 2017. Genomic reconstruction of the history of native sheep reveals the peopling patterns of nomads and the expansion of early pastoralism in East Asia. Mol. Biol. Evol. 34:2380-2395. https://doi.org/10.1093/molbev/ msx181. 